\title{
Access To Literacy Empowerment Through Systematic Interventions: English Literacy Benchmarks In Kenya
}

Agnes W. Gathumbi, (E-mail: AgnesGath@africaonline.co.ke), Kenyatta University, Kenya

\begin{abstract}
English language in Kenya has been given a higher status as compared to other languages. Apart from being the official language, it is the language of instruction from primary four upwards. Stakeholders also regard it as the language of social and economic upward mobility. Recognition of English mastery notwithstanding, there is evidence that the reality in the school system is far below the ideal. Although the shortcomings in the mastery of literacy in English in Kenyan primary schools are associated with a number of factors, studies done in this area have not delved into detailed intervention approaches needed to improve English Literacy in primary schools. It was therefore, important to develop benchmarks as standards to inform policy makers, curriculum developers, teachers, teacher trainers and materials developers. This paper reports the results of a nationwide study aimed at reducing illiteracy in Kenya by developing interventions in form of English Literacy benchmarks for primary grades 3 and 6.This study was done by a team of Research and Development researchers, with the support of the Rockefeller Foundation. This is the first time attainment standards of any kind have been developed in Kenya.
\end{abstract}

\section{INTRODUCTION}

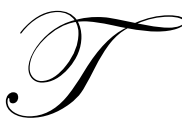

he need to develop English literacy norms for primary schools in Kenya arose after the realisation that the majority of primary school were leaving school still illiterate or semi-literate. Lack of literacy skills acts as an impediment to acquisition of knowledge, both in and out of school. Production of semi-literate people after investing heavily in their education is not cost effective. It also inhibits development of a country, both socially and economically. At this juncture, it is important to discuss the term, literacy as it is used in this paper.

There is no specific definition of literacy agreed on by scholars but for the purposes of this study, literacy in English encompasses the ability to use and integrate the four basic language skills of listening, speaking, reading and writing in various contexts, which also include knowledge of grammar and vocabulary. Literacy also involves use of creativity, viewing and critical thinking. In Kenya, literacy is seen as the single most important tool the school can give to the child. It is central to and influences all his/her subsequent learning of the target language, which in this case is English, other subjects and general educational development. The acquisition of literacy and numeracy is associated with the more general cognitive, psychomotor, affective and social domains that are usually the central aim of schooling (Wells, 1986).

In its broader sense, literacy goes beyond the prosing of operational skills. It helps the child to think about the language they are meeting and subsequently the language they themselves use. Language and literacy are bound up forms of socialisation, in this case, into the mainstream ways of using language in speech and print; into the mainstream ways of taking up meaning which involves making sense of experience. Language is intimately bound up with the process of education at all levels. It can be said to be much more than education but on the other hand, education is much more than language and yet neither can be extricated from the other, each entails the other. 
Most Kenyan children enter school for the first time by age five or six, many of them having not gone through pre-school, especially in rural areas. As soon as they enter school, they are taught subject area content. At the same time, they are expected to listen with understanding, learn to speak, read and write in the target language and, by the time they are seven or eight years old, a substantial part of their learning is dependent on their ability to cope with written language (Wells, 1986). Proficiency in the basic skills of listening, speaking, reading and writing has to be acquired before one can act in a literate manner. The teaching of literacy must therefore, be systematic and sequential in operation. The effects of literacy learning and practice on the acquisition of cognitive processes depends on the kind of literacy activities that the learners are engaged in and the kind of cognitive processes inherent in those literacy practices. When the range of functions and complexity of literacy activities is limited, then the cognitive skills fostered by literacy activity will also be limited.

Not all children who come to school, however, find it easy to adjust and learn. Some children find it a little difficult in mastering the skills required, to fully benefit from the enormous opportunities that literacy opens up to them. To these, the written word and spoken language has little meaning and therefore, they find it difficult to cope. Those who are prepared adequately make it a success and progress steadily; those ill equipped don't make as much progress and, most often than not, come to be seen and see themselves as failures. In this research, when the normsbased criterion-referenced tests were administered to a representative sample of learners in primary grades 3 and 6 , it was found out that in the provinces where the English literacy levels were low, there was also a high drop out rate of pupils. There was a need therefore, to look for a way to enhance the acquisition of this literacy by the majority of the children, especially in the rural and urban slums. One of the interventions was to develop English literacy norms.

\section{ENGLISH LITERACY NORMS (ELN)}

Language norms refer to language forms that are socially accepted as correct, often to be found in grammars. In constructing grammars therefore, linguists collect utterances and judgements about the correctness of these utterances to form the basis of the grammar (Stern, 1983). As such, norms are not orders or prescriptions issued by a superior (the linguist) to a subordinate (the speaker). Only general prescriptions, which are accepted by the speakers are the norms for them. This means that when linguists construct grammars, they are trying to come up with the language norms of the given language community. However, who is consulted in the norm formulation endeavour has implications on what is judged to be the norm. Stern (1983) writing about norms says,

As native speakers we possess norms of language against which we can judge utterances that we hear or produce. We can interpret or make sense of deviant utterances as if they were formed correctly.

From the foregoing, the term 'norms' is used to mean standards or the intuitive knowledge of the rules, which are in the subconscious (but which can be made conscious). Such rules are applied in the use of language. As Stern puts it, the native speaker has the intuitive grasp of the linguistic, cognitive and socio-cultural meanings expressed by language forms. For second language speakers to be said to 'know' a language, they have to attain this level though in different degrees of 'knowing'. Norms are therefore important in approximating such proficiency in a language. It is important to note that the aim is not to acquire the native speaker's accent but to be able to use the language fluently and appropriately to perform various functions, be they formal or informal.

The fact that the native speaker's competence or knowledge of the language is always used as a necessary point of reference for the second language proficiency concept, can be problematic when considering issues of norms. It is also important to consider the notion within the context of second language learners. And this is why Ryanga (1994), quoting from Romey (1968) underscores the importance of using valid grade norms to identify a demonstration of minimum level of competence for second language learners with typical mother tongue. As she puts it, unless certain standards are achieved promotion of a student to a higher class is counterproductive. This indicates that specified norms are vital for ensuring some certain standards of proficiency are kept or assured. This is more so in cases where mother tongue interferes with the learning of a second language. This is the case in Kenya and in other Anglophone countries where English is learnt as a second language in multilingual contexts.

Within the testing domain, norms refer to typical performance for clearly defined reference groups. A norm is therefore, the score or quotient on a test above or below what has been found to be typical of that age group. 
Age norms refer to values representing typical performance of people of a certain age group. The term norm in this case suggests comparison with others. Typical performances or norms vary with time, as what might have been typical performance 20 years ago may not be today.

\section{RATIONALE FOR THE DEVELOPMENT OF ENGLISH LANGUAGE NORMS}

There is a need to link an individual and social development. For equitability in basic education, all pupils should be able to achieve an acceptable level of learning in order to become useful citizens. Setting norms or learning competences ensures that step-by-step order is followed in the development of the curriculum. Such a curriculum will in turn ensure lower order aspects are understood before moving on to higher order ones. This would in turn help more children acquire the basic learning competencies expected at various levels, without hindering the upward mobility of those pupils with higher order competencies.

Use of norms ensures pupils are not hurried along in order to complete the syllabus without first learning what is expected of them as is the case in Kenya today, and neither are they held back to be in step with those who do not understand or assimilate what needs to be learnt. Each learner is taken as an individual. Setting of language norms also makes sure pupils; irrespective of the social class, regional disparity, race or creed have access to at least the basic education that will make them become literate citizens who can function competently in the world of work.

Setting teaching standards help a curriculum developer to develop a curriculum that is suitable for learners at various levels. Writers of educational materials are well informed and are able to develop competence-based materials. They will also be able to provide broad guidelines to teachers to adapt teaching strategies that would promote the expected learning competencies. Teacher educators would also gain and alter their training procedures geared towards attainment of the expected language proficiencies. Examinations would also be redesigned in terms of the set norms and they would provide a basis for certifying pupil's achievement of specific English language skills.

\section{KENYA'S LANGUAGE POLICY AND THE STATUS OF ENGLISH LANGUAGE}

The language policy of a country can influence inter alia the teaching/learning process. For it to succeed the language policy should be well understood, its benefits well articulated to the stakeholders and it should also be consistent in its implementation. The parameters of this study were derived from requirements in Kenya's language policy which states that: (1) the children's first language (either mother tongue or the language commonly spoken in the school's catchment area) should be used as the language of instruction (LOI) in primary classes 1 - 3, (2) English should be taught as a subject in lower primary, and (3) English should be used as LOI from the beginning of primary class 4, upwards. In practice, however, primary schools do not adhere to this policy (Gathumbi, 1985; Muthwii 2001).

In this study, it was found that parents, pupils and teachers support the policy position because they perceive English as the key to further education and social economic development. Gathumbi (1985) found out that lack of adherence to the language policy in Kenya was largely influenced by national examinations, which were conducted in English. Teachers did not, therefore, see the need to use the mother tongue. The most common practice in teaching is to use a mixture of first language, Kiswahili and English as languages of instruction, even when the language policy states otherwise. A less common but significant practice is for some schools to use English as LOI right from the beginning of the first primary school grade. These practices do not only go contrary to the language policy but they are also an impediment in learning the content when learners are taught in a language they do not well understand, especially in lower grades.

Research literature that reflects psychological theories of language acquisition and development, and precepts of social-cultural evolution takes the view that in education, the learners' first language (L1) ought to be developed as the (LOI) so as to foster the evolution of a truly indigenous way of life in formerly colonized societies (Rubagumya 2000). However, most African stakeholders in education see English as part of the current reality and an important tool in socio-economic development. In spite of the conviction that local languages have a role and ought to be taught in schools, most respondents in this study held the view that English should be given increasing 
emphasis as the primary school course progresses. Stakeholder's main concern was the role of English in and beyond the school. These findings concur with the widely reported demand in formerly colonized countries for formal education to inculcate mastery of widely spoken (largely metropolitan) languages (Abdulaziz, 1982; Dutcher, 1995; Lopez, 2000; Rubagumya, 2000).

The views of beneficiaries, both in primary and secondary schools, suggest that English is perceived as a language of power/status and is preferred to mother tongue. When a child is able to speak English fluently at an early age, such as at pre-school level, it is a source of prestige for most parents in Kenya. This has been the case over the years as reflected by the following comment by Whitely (1974).

"One of the main incentives of African parents in sending their sons to school is for them to acquire knowledge of English ... the principle means by which economic advancement can be obtained in later life.

As a result of this pressure, there are concerted efforts, mainly by urban teachers, to ensure learners speak in English right from lower primary, regardless of the language policy statements. Despite this, concern has also been expressed by the government, interested individuals and the media about declining English language standards in the country.

\section{LACK OF LITERACY IN ENGLISH}

It has been alleged that most pupils in primary school cannot communicate effectively in English by the time they reach class 4 as the primary school syllabus expects them to. Negative reports and sentiments have been consistently echoed in the media and other academic forums regarding the way English is taught in schools and performed in examinations. An article in the Standard Newspaper of February 10, 1993, claims were made that English language standards were dropping, university undergraduates could hardly write job application letters without making syntactic, punctuation and spelling errors. Many of the graduates found it difficult to hold a continuous conversation in English without the use of sheng (slang: a combination of Kiswahili and English).

During a national seminar in 1993 titled, "English across the Curriculum" language specialists argued that English standards in Kenya had been falling. This, they said, was evident right from primary to university level. Other sentiments expressed during the same seminar were that most pupils in primary schools could not communicate effectively in English by class 4. As a result of this, they were ill prepared to be able to perform well in English across the curriculum from class 4 upwards. Research done by Ryanga (1994) and Kirigia (1991) associate low proficiency and lack of confidence in the use of English, with slow progress in attaining adequate knowledge. Kenyan Primary schools do not give learners the opportunity to express themselves to nurture their language mastery and proficiency.

Learners who cannot express themselves intelligibly in English have been found to perform poorly in other subjects. The pupils do not perform poorly because they do not understand the subject matter but because by lacking the speaking skills, it is more likely they will also lack the necessary reading and writing skills required in examinations. For example, in this study many learners in class 6 were unable to narrate in English an activity they normally do every day but when asked to narrate the same in the mother tongue, they were happy to do so and they narrated enthusiastically. This implies that the learners have the ideas but they lack the tools to express them. Further more, in schools where the majority of teachers come from the same ethnic background, they often speak in their mother tongue, within the hearing of their pupils. Consequently, feelings of defiance are created when teachers compel pupils to communicate in English. They find this to be a punishment. It has been observed that at primary and in most secondary schools, learners find all excuses not to use English and only use it if they have to. Lack of exposure may have also contributed to the poor performance in English.

In the past, there has been a tendency to depend too much on anecdotal evidence and intuition, hence the need for more informed analysis to form a basis for decision making (SACMEQ, 2001). No study has yet delved into the detailed intervention and approaches concerning improvement of English literacy in primary schools, hence the ELN project intervention which addresses the issues of LOI as well as explores the extent to which wrong practice of LOI continually hampers the acquisition of desirable learning competencies. 
Major weaknesses in the policy are its failure to adequately address human and material resources especially for MT languages. The implications are that the learners who are expected to transit to English medium at class 4 have not acquired enough knowledge of mother tongue to be able to use it as a basis for learning English as a second language. The implementation is also flawed as most teachers are ignorant of its requirements.

\section{FACTORS ASSOCIATED WITH THE DECLINING STANDARDS}

A number of factors have been associated with the declining English literacy standards. Firstly there is lack of adequately trained English language teachers at all levels. Enrolment data from the MoEST show that over 50\% of the trainees at various PTTCs had performed poorly at their Kenya Certificate of Second Education (KCSE) examination that is done after four years of secondary education, as they had attained grade ' $\mathrm{D}+{ }^{6}$. For many years, the overall minimum requirement grade for the trainees has been ' $\mathrm{D}+$ '. However, for the last four years, up to 2003, the minimum aggregate entry grade has been a plain ' $\mathrm{C}$ ', regardless of whether one had failed in English, even though s/he was expected to teach in English after two years of training. Further more, much of the training emphasizes general teaching methodology and little time is spent on training how to teach English language skills that many of them lack. The majority of practicing primary school teachers, (over 90\%), went through this system. After educationists and parents expressed concern about the quality of teachers and pre-service teacher trainees, the government this year (2004) changed the admission policy. Everyone aspiring to be a teacher has to have a pass grade of ' $\mathrm{C}-$ ' in English and Mathematics at KCSE.

Secondly, for many years parents had to provide virtually everything for the education of their children, except teachers' salaries. The majority of them could not afford due to financial constraints. This resulted in lack of textbooks for individual pupils to be able to work independently. In most rural schools, the ratio of textbooks to learners has been 1:4 on average. This situation is expected to improve slightly as in 2003 , the government through donor funding, started providing textbooks and other learning materials to all public primary schools. The sharing ratio now is 1:2 in upper primary and 1:3 in lower primary. There is lack of libraries in most schools and where they exist, they are poorly stocked.

Thirdly, in most schools there exist large classes that inhibit individual attention. In such a situation teachers opt to use the "chalk and talk" method where learners are passive listeners. This situation has been aggravated by the introduction of free primary education where high enrollments ( 1.3 million) have caused the teacher-pupil ratio to be very high: 1:100. Teachers find it difficult to teach as they have not been trained to handle such large classes where age groups in one classroom vary. The teacher does not interact with the learners in a oneto-one basis, hence may not know whether they have grasped what was taught. Teachers are also poorly remunerated which has resulted in their low morale.

Fourthly, there is inadequate implementation of education policies and objectives. Teaching has become so examination oriented that both learners and teachers are judged on the grades obtained at Kenya Certificate of Primary Education (KCPE) examination done nationally as a terminal primary education examination. The examination is norm-referenced and schools are ranked according to the national mean grades obtained at KCPE examination. This type of testing has had negative backwash effect on teaching and learning in the classroom. Acquisition of language skills for use in the present and future takes a back seat as a grade determines if one is a success or failure. It has been claimed that learners cram the curricula content without care of developing the necessary functional skills. There are also claims that as it is the practice in schools, primary teacher educators too are beginning to confine themselves within the parts of the syllabus that are often tested in the KCPE examinations. These are reading and writing skills, ignoring listening and speaking skills that are not examined. The pre-service teachers too are also becoming slaves to the same examination.

The current government policy on the quota system in secondary school admissions is that $85 \%$ of students in a provincial school should come from the home province. This has encouraged use of mother tongue instead of English since majority of the learners are monolingual. Since the intake to teacher training colleges is also based on the quota system, the pre-service teachers that have no mastery of the English language usually end up teaching in the same schools in the same province. The cycle then continues. Lewin (1983) says that the quality of a teacher determines the quality of education. 
As the language policy in grades 1-3 is trilingual, there is a need to review the language policy since pupils have no mastery in either English or Kiswahili or mother tongue. The number of lessons allocated to teaching English need to be increased in the primary school curriculum. English being taught as a second language requires long hours of exposure and instruction to improve the learners' competence in all the skills. Fluency in the LOI would mean an improved performance in all the other subjects in the curricula. Reduction of exposure time from ten to seven lessons per week has led to difficulty in sufficiently exploring all the language skills in a L2 learning situation, especially where exposure to the target language outside the classroom is minimal as is the case in the rural schools.

From the foregoing it is obvious that the development of literacy is a key issue in the intellectual development of a person. It is paramount that we enhance it by developing the mechanism through which it is delivered. Key among these is the LOI, which happens to be English in Kenyan schools. There is need to have an effective language policy to be used in the teaching -learning process. This should be well understood, its benefits well articulated and it should be consistent in its implementation.

In this study, focus was on literacy in English as a language of instruction in Kenyan primary schools. Areas of interest included methods of training for the teachers, types of learning aids and materials used current practices in schools and teaching approaches, methods of assessment and views of the various stakeholders on all these.

Some researches had been done on literacy in Kenya. However, given the variety of purposes and objectives of such studies, they have not sufficiently delved into detailed intervention approaches needed to improve English literacy in schools. The discourse had tended to be focused on macro-issues (such as the relationship between language in school and the culture of the evolving society) rather than on detailed planning and practical implementation in schools, the exception being attempts by the Kenya Institute of Education (KIE) and the Kenya National Examinations Council (KNEC) to incorporate some aspects of theoretical precepts of language into curriculum development and assessment through public examinations.

It is for the above reasons that this study made an attempt to address the problem by developing systematic interventions. In order to develop literacy in English, there was a need to come up with acceptable English language attainment benchmarks or norms as milestones to be used in primary schools. The purpose is to enable the majority of learners to achieve an acceptable level of learning in order to become literate and functional citizens. Setting norms ensures that a step-by-step order is followed in the development of the curriculum. Another positive effect is the use of appropriate teaching methodologies by well-trained and qualified teachers. The methods used to assess the learners' learning outcomes must also be in harmony with the curriculum and teaching strategies used.

\section{NORMS HYPOTHESIS}

Norms have been given various terms such as benchmarks or attainment levels. They have also been defined variously. For our purposes here, a norm is defined as an articulated desirable standard to be attained for a specified level. It is synthesized from a variety of sources pertinent to teaching / learning English language, for the purposes of measuring proficiencies.

Development of English Literacy Norms (ELN) for primary schools in Kenya involved hypothesizing minimum and desired literacy levels that learners should acquire in the four macro skills, namely listening, speaking, reading and writing, as well as in grammar and vocabulary. These are benchmarks specifying English language competences expected to be attained in primary classes 3 and 6 . They are aimed at achieving both linguistic and communicative competences, among other things. The project developed benchmarks on which literacy in English language can be gauged at primary classes 1,2 and 3, and at classes 4, 5 and 6 .

Hypothesising of the English literacy norms started by first establishing a need for them. This was done by identifying the critical variables that were found to negatively affect quality education. The major one was lack of literacy in English that is the LOI. Lack of literacy in English meant lack of literacy in other subjects. The parents too were also quite clear what skills they wanted their children to learn. The first among them was literacy in 
English language. This was followed by a literature review on literacy and norm development. The purpose for this was to first and foremost establish the possibility of developing norms for Kenyan primary schools, as this was going to be a major innovation. Secondly, there was a need to learn from those who had developed education norms before. It was necessary to find out what drove them to develop the norms and the challenges they faced in the process. This was vital before the onset to avoid or minimize the challenges that may have been encountered.

\section{STAKEHOLDERS' VIEWS}

The stakeholders' views were important as they had a stake in the education of Kenyan citizenry. There was, therefore, a need to find out stakeholders' views concerning English language literacy levels of primary school learners and school leavers. The sample comprised education officials, primary school teachers, secondary school teachers, tutors from primary teacher training colleges, business people, parents, NGOs, faith groups and parents. Stakeholders' data were collected through questionnaires, semi-structured interview schedules, and focused group discussions.

Questionnaires were developed from hypothesized predictor factors. They were administered to curriculum deans and heads of English in four primary teacher training colleges, heads of the sampled schools, four primary school teachers who taught English to grades 3 and 6 pupils in each school and also to 100 form one secondary school teachers who taught English. The questionnaires were aimed at drawing views and other information from the world of perceptions of the stakeholders. Questions sought information about their understanding of the term 'literacy' and also what English literacy skills they expected primary school learners to possess.

Semi-structured interview schedules were administered to primary school teachers, government officials, business people, NGO officials and senior members of Faith groups. Focussed group discussions were also held with the parents of pupils in primary grades 3 and 6 . The purpose of this was to find out what they understood by the word literacy. There was also a need to find out what their expectations were after their children finished eight years of primary schooling.

The focus in all the instruments used, was on the four macro skills of language acquisition namely, listening, speaking, reading and writing. Pedagogic factors were also considered. Most questions were similar in all the instruments. Such triangulation that sought views from different respondents on similar issues enriched the data. Nevertheless, some questions were specific to particular samples.

The rationale for selecting the sample was to get a variety of views. It was necessary to know parents' expectations after investing heavily in the education of their children, Primary school teachers' views were sought as they have implicit norms since they engage in teaching. The other stakeholders interact with school leavers in one way or the other, either in the world of work or in other places outside the school. Expectations of business people, NGOs and Faith groups were of interest as they are the recipients of school leavers. Form one secondary school teachers provided valuable information as they were able to point out weaknesses that they normally observe in the first year students when they join secondary school. It is more likely the problems could have been rectified if teachers had any standards to base their teaching on. Education officials too have a stake in the education system as they are the administrators who are responsible for ensuring the curriculum is implemented as expected and the quality of education is maintained.

\section{CLASSROOM OBSERVATION}

After collecting stakeholders' data, it was found out that they had some expectations in the school leavers. It was therefore, important to study classroom teaching to find out whether the stakeholders' expectations were being fulfilled. The same schools used during stakeholders' data collection were used for classroom observation purposes. Classroom observation was done using a specially constructed observation schedule. The aim was to find out whether learners were being given an opportunity to acquire the skills expected by the stakeholder. It was found out that much of the teaching was teacher-centred and pupils were hardly ever provided with any opportunity to express their ideas. 'Teacher-talk' dominated classroom teaching, giving the learners little time to practice the learnt skills. They were just passive listeners who expected to be provided with knowledge by the teacher. The scenario 
was much more conspicuous in rural schools where learners were greatly disadvantaged in all the skills, especially the speaking skills. Lack of exposure to the language skills might be one of the reasons why they performed poorly. Teachers themselves did not possess the expected English language competences as they kept on code-switching between Mother tongue, English and Kiswahili, in the process of teaching. This was done in grade six where teaching should be in English according to the language policy.

\section{DOCUMENT ANALYSIS}

The primary English language curriculum is accompanied by a syllabus, textbooks and other materials. Achievement of the objectives stated in the syllabus is assessed after eight years of primary schooling. It was, therefore, necessary to conduct an analysis of these educational materials, as well as others, that influence development of English literacy, either directly or indirectly.

Document analyses were done using an analysis guide, specially developed for this purpose. The analyses were done through studying various materials used in the primary school curricula. The task involved studying the content and identifying the skills emphasized in the primary English language syllabus and in the recommended English language textbook. Analyses of recommended Science, Mathematics, Geography, History and Civics (GHC) textbooks were also done. The aim of studying non-English textbooks was to identify the English language competences expected from the learners, to be able to access the content. Analysis was also done on KCPE examination papers for the previous three years, from year 2001 backwards, to find out what language skills were being tested and the competence levels expected. Data emanating from the analyses was also used in the hypothesis of the ELN.

The purposes of these activities were to find out what the society expects from the education sector, what the syllabus says about what should be learnt, how the materials capture what the syllabus recommends, the type of examinations set and the skills tested. The issues being raised elsewhere concerning language learning and development of literacy norms were of interest to the researchers. The analyses also helped to refine the predictor data questionnaires that were used alongside the criterion-referenced tests developed from the norms.

\section{THE NORMS}

Arising from the collected and analyzed data from various sources, English literacy norms for classes 3 and 6 were hypothesized. The norms are in four columns: the first one states the norm and the next contains performance indicators that state in more detail the nature of performance expected in each norm. This is followed by a column showing the minimum levels of competence expected. The last column contains the desired competences for each norm. Minimum and desired competence levels were arrived at by looking at the data generated prior to hypothesizing the norms as explained above. Examples of how to use the norms and definitions of some difficult terms have also been given, where it was felt necessary.

Compiling all the resultant information yielded the following sets of hypothesized literacy norms:

Class 3: Listening 10 norms; Speaking 17 norms; Reading 17 norms; Writing 24 norms, and Grammar and Vocabulary 9 norms.

Class 6: Listening 15 norms; Speaking 16 norms; Reading 17 norms; Writing 20 norms; and Grammar and Vocabulary 10 norms.

The norms are aimed at informing the practising teacher, the teacher educator, curriculum developer, the policy maker, and educational materials developer. They help to show the expected language competences at each level which, when used by stakeholders would go a long way to promote quality education. The norms are also used in developing diagnostic criterion-referenced tests that could be formative and/or summative. 


\section{CHALLENGES}

In the process of developing English literacy norms, researchers faced some challenges. In the first place, it was the first time literacy norms were developed in East Africa and very little was known about it. As such we did not have a point of reference as there were no local experts in this area.

Secondly, literature review on norms and norms development came from the western countries like America and Australia, where English is the first language. The norms that were closer home were those from Mauritius but even then, the two language learning environments are different.

There were also the problems of deciding on the appropriate format and how to formulate the norms in a way that they did not look like another English language syllabus. Three drafts were written before we could agree on one that presented the norms in a way that they could be easily understandable and of benefit to the teachers. This required the researchers to avoid technical linguistic terms and to look for simpler ones that were easily understood. There was also the need to look for appropriate examples to accompany the norms where necessary. This took some time and in some cases they were not readily available.

The problem of deciding what could be termed as minimum competence and what was considered to be at the desired level of competence was quite challenging. Due to lack of local reference, competence levels stated in norms from other countries were studied with the aim of adapting them to fit the Kenyan situation. Of special interest were norms from Mauritius as they were developed to be used in a second language learning environment like that of Kenya. We had also to use the syllabus to get the content expected to be taught at the two levels. Satisfying stakeholders' aspirations was important too. In a few cases, we had to use our own discretion from our own teaching experiences and as local educationists, to arrive at the expected competence levels of literacy in English.

\section{ASSESSMENT BASED ON ENGLISH LITERACY NORMS}

There was a need to know how the desirable literacy levels would be assessed. The type of assessment to be used has to reflect the objectives chosen in developing literacy norms. Decisions had to be made on whether assessment would be through testing the listening and speaking skill (a method not currently used to test English language proficiency in Kenya), or only through reading and writing as is the practice currently. If stakeholders want school leavers to be able to communicate fluently in the target language, both in the spoken and written form, then tests that measure pupils' ability to communicate verbally should be administered. The ability to read was also highly rated. The hypothesized literacy norms ensured these skills were well articulated to be able to set valid and reliable test items.

It was necessary, therefore, to create a test that would require learners to show how well they can use specific features of the language, and also demonstrate that they understand how such features operate within naturalistic discourse. To develop tests that required learners to exhibit their communicative competence, it was important to focus on performance tasks in all the language skills. Tests were developed from the norms with the aim of trying to establish the English literacy competence levels present among the learners at the two levels. The tests were administered to a representative sample nationally. The results showed that the literacy in English language had not changed since the SACMEQ study. Over $70 \%$ of the learners failed to attain the desirable literacy levels.

\section{TEACHER'S RESOURCE}

After hypothesizing the ELN, they were found to be too general and academic for the ordinary primary school teacher, as some English technical terms were used. There was therefore, a need to disaggregate the norms by defining the terms that were perceived to be difficult and adding details that were lacking to help the teacher.

The format used in writing the Teacher's Resource makes it easy for the teacher to use it. There are five columns. The first one contains the norms where the perceived difficult words are defined and explained. Details of 
what the norm means in terms of teaching and learning are also given. The second column helps the teacher to understand the competences that need to be developed for each norm. Examples of the competences to be developed are given and also definitions of difficult or technical linguistic words, whenever they are used. The third column helps the teacher to assess attainment of the stated competences. Suggestions of possible assessment techniques are made. Below the three columns are other two. The first one explains to the teacher the possible learning activities in the classroom and the second column provides further enrichment activities that can be done by the learners after the actual teaching. Possible teaching and learning resources are also suggested. Two different resources have been developed from grades 3 and 6 hypothesised norms. The Teacher's Resources are not meant to replace the syllabus but instead to complement it. They are expected to be used as reference materials. The following two samples show how one class 3 English literacy norm looks like in the original draft and also in the Teacher's Resource book.

\section{SUMMARY}

The purpose of this paper was to give the purpose and a detailed account of the methodology used in developing English literacy norms for primary schools in Kenya. From the foregoing it is obvious that the development of literacy is a key issue in the intellectual development of a person. It is paramount that we enhance it by developing the mechanism through which it is delivered. Key among these is the language of instruction, which happens to be English in Kenyan schools. There is need to have an effective language policy to be used in the teaching -learning process. This should be well understood, its benefits well articulated and it should be consistent in its implementation.

In order to attain expected English competences, there was a need to come up with acceptable English language norms for use in primary schools. All pupils should be able to achieve an acceptable level of learning in order to become useful citizens. Setting norms ensures that step-by-step order is followed in the development of the curriculum. Together with this, is the use of appropriate teaching methodologies and approaches by well-trained teachers. The methods used to assess the pupils learning outcome must also be in harmony with the curriculum and teaching approaches used.

In this study focus was on developing an intervention that would arrest the problems of attaining literacy levels in English, as it is the language of instruction in Kenyan primary schools. Since students in Kenya are second language speakers of English, it is important that the established norms are adhered to. Setting the norms ensures that a systematic order is followed in the development of the curriculum, teaching and learning materials and in the teaching process. In developing norms for grade 3, it was assumed that, if a teachers had benchmarks which pupils in grade 3 must demonstrate, they would be encourage to consider such demonstration of competency to be a prerequisite to using English appropriately as a language of instruction from class 4 upwards. In developing the norms for class 6 , it was assumed that there is a certain level of competence pupils would have to demonstrate if they were going to be able to read and answer questions set by the KNEC in all subjects tested in English, at the end of the 8 year primary school course. Testing of some language skills and leaving out others that are also in the curriculum causes a negative backwash effect. So testing should test the whole syllabus. Where norms are present, both textbooks and non-textbook materials would be developed with the norms in mind.

The process of developing the norms entailed using a wide variety of sources such as existing literature, document analyses of the formal curriculum including the English syllabus and textbooks in English, Mathematics, Science, Geography and History and Civics (GHC). Past examination papers were also analyzed. Document analyses enabled the identification of the English language skills and levels of competency the learners need in order to effectively handle different subjects. Opinions from stakeholders were also sought.

Development of English Literacy Norms (ELN) for primary schools in Kenya involved hypothesizing the norm by clearly stating what it is, stating the performance indicators that show what the learner is expected to do to satisfy the requirements of the norm. The minimum and desirable competence levels that learners should acquire in the four macro language skills of listening, speaking, reading, writing, grammar and vocabulary for grades 3 and 6 were also stated.. These are milestones or benchmarks specifying English language competencies expected to be attained at these two levels of primary education. The benchmarks are aimed at achieving both linguistic and communicative competences in learners. The rationale for selecting primary classes 3 and 6 was because class 3 is 
the transitional level when learners stop learning in mother tongue as the medium of instruction and change over to English as the medium of instruction at primary class 4 . It is important at this level to ensure learners have adequate English language competences to be able to cope with the challenges of learning English and other subjects in English. At primary 6, learners start preparing for the final primary education examinations done after eight years of learning.

It is believed that when literacy in English is developed, learners will have access to knowledge that require such competences. Areas of interest include methods of training for the teachers, types of learning aids and materials used, current practices in schools, teaching approaches, methods of assessment and views of the various stakeholders on all these. It is hypothesized that by using the ELN and the Teacher's Resource, both teachers and learners will see a marked improvement in the development of literacy, as well as in performance at school and in the national examinations.

\section{REFERENCES}

1. Abdulaziz, M. (1982). "Patterns of Language Acquisition and Use in Kenya: Rural-Urban Difference". In International Journal of Society and Language. 34. (1982) pp 95-120.

2. Ayot, H. and Patel, M. (1992). Instructional Methods. Nairobi, Educational Research and Publications Ltd.

3. Carson, D. (1990). "Language Policy Across the Curriculum", Multilingual Matters.

4. Cummins, J. (1980). "The Construct of Language Proficiency in Bilingual Education.” In Alatis 1980:81103.

5. Dutcher, N. (1985). The Use of First and Second Language in Education: A Review of International Experience. Washington D.C.: The World Bank.

6. $\quad$ Ellis, R. (1994). The Study of Second Language Acquisition. Oxford: Oxford University Press.

7. Gathumbi, A.W. (2004) "Attainment of English Literacy Skills in Primary Schools in Kenya. CriterionReferenced Testing as the Alternative Solution". Paper Presented in the Association of Third Word Studies Conference, Baraton University, Eldoret, Kenya.

8. Gathumbi, A. W. (2004) "The Impact of Language on Science and Mathematics Education". Paper presented in a conference of Teachers of Science and Mathematics, Kenyatta University, Nairobi.

9. Gathumbi, A. W. (2004) Principles and Techniques in Language Teaching: A Text for Teacher Educators, Teachers and Pre-service Teachers. Jomo Kenyatta Foundation, Nairobi

10. Gathumbi, A. (1985). "Effects of Language Policy on the Mastery of English at Standard Four - A comparative study". A PGDE Dissertation, Kenyatta University, Kenya.

11. Gorman, T.P. (1974). "The development of language policy in Kenya with particular reference to the educational system". In W.H. Whiteley (ed.) Language in Kenya. Nairobi: Oxford University Press. pp. 143-170.

12. Hymes, D. (1972) “On Communicative Competence”. In Pride and Holmes 1972:269-93. Kenya National Examination Council (1994). K.C.P.E. Newsletter 1994. Nairobi.

13. Kirigia, E.K. (1991) "Assessment of English Reading Comprehension of pupils completing Primary Education: A case study of Meru Municipality". M.A. Thesis.

14. Lopez, L.E. (2000a) "Conditions for Success in Designing and Monitoring Programme Delivery in Multilingual Settings". In Distance Learning Course on the Language of Instruction in Basic Education. Washington DC. The World Bank Institute.

15. Lopez ,L. E. (2000b): "Cognition, culture, language and learning: an introduction for educational planners in multilingual and multicultural contexts. In Distance Learning Course on the Language of Instruction in Basic Education. Washington DC. The World Bank Institute.

16. Mbaabu, I. (1996) Language Policy in East Africa. Nairobi: Educational Research and Publications.

17. Muthwii, M. (2002) Language Policy and Practices in Education in Kenya and Uganda. Nairobi: Phoenix.

18. Parry, K. (ed) (2000). Language and literacy in Uganda: Towards a sustainable reading culture. Kampala: Fountain Publishers.

19. Republic of Kenya (1981). Report of the Second University: Mackay Report. Nairobi: Government Printer.

20. Republic of Kenya (1998). Master Plan on Education and Training 1997-2010. Nairobi: Government Press. 
21. Rubagumya, C.M. (2000) "Choosing the Language of Instruction in Post-colonial Africa: Lessons from Tanzania". In Distance Learning course on the Language of Instruction in Basic Education. Washington D.C. The World Bank Institute

22. Ryanga, C.S. (1994) "Construction and Standardization of an English Language Literacy Test for Upper Primary School Grade in Kenya". Ph.D. Thesis.

23. Stern, H.H. (1983). Fundamental Concepts of Language Teaching. Oxford University Press.

24. The East African Standard, $29^{\text {th }}$ May 1983. Nairobi.

25. The Standard Newspaper, 29 May 1993, Nairobi

26. The Standard Newspaper, $10^{\text {th }}$ February 1993, Nairobi.

27. Weir, C. (1990). Communicative Language Testing. London, Prentice Hall International

28. Wells, G. (1986). The Meaning Makers: Children Learning Language and using Language to Learn. London, Hodder and Stoughton.

29. Whiteley, W.H. (ed) (1974). Language in Kenya. Nairobi: Oxford University Press.

A Sample Of A Class 6 Norm

\begin{tabular}{|c|c|c|c|}
\hline Norm & Performance Indicators & Minimum Competences & Desired Competences \\
\hline $\begin{array}{l}\text { 1. Responding } \\
\text { to simple } \\
\text { questions, } \\
\text { commands, } \\
\text { instructions } \\
\text { and requests }\end{array}$ & $\begin{array}{l}\text { Ability to: } \\
\text { - listen with understanding } \\
\text { - answer simple questions } \\
\text { - respond to simple commands } \\
\text { - follow simple instructions } \\
\text { - respond to simple requests } \\
\text { - make simple question. } \\
\text { - Give simple commands } \\
\text { - Give simple instructions } \\
\text { - Make simple requests }\end{array}$ & $\begin{array}{l}\text { Ability to: } \\
\text { - Answer simple Yes/ No questions. } \\
\text { - Answer True/False questions. } \\
\text { - Respond to single commands correctly } \\
\text { - Follow single instructions correctly. } \\
\text { Respond to single requests correctly }\end{array}$ & $\begin{array}{l}\text { Ability to: } \\
\text { - Respond to wh- questions } \\
\text { - Respond to a series of } \\
\text { commands } \\
\text { - Respond to a series of simple } \\
\text { instructions } \\
\text { - Respond to a series of } \\
\text { requests } \\
\text { - Listen to questions and ask } \\
\text { similar questions } \\
\text { commands and give similar } \\
\text { commands } \\
\text { Listen to instructions and give } \\
\text { similar ones } \\
\text { Listen to requests and make } \\
\text { similar ones. }\end{array}$ \\
\hline
\end{tabular}


A Sample Of The Same Norm In The Teacher's Resource

\begin{tabular}{|c|c|}
\hline & rmm \\
\hline & $\begin{array}{l}\text { Responding to simple questions, } \\
\text { orders/commands, instructions } \\
\text { and requests. }\end{array}$ \\
\hline
\end{tabular}

If we want someone to do something we make a request or a command. The ability to respond will depend entirely on whether the recipient of information has listened and understood or not. The linguistic level of learners should be taken into consideration.

Once something has been said, the only way of knowing whether it has been understood or not is by observing if an appropriate response is given, be it verbal, non- verbal or written. For example, responding correctly to a command like: Everybody stop writing and put your pens down! (at the end of an exam) shows the command has been understood. None response might mean the command was not understood and something needs to be done.

By granting an opportunity for responding to simple commands, questions about self, instructions on doing a simple activity such as drawing a picture and use of etiquette when making requests, the teacher is in essence, allowing the pupils to express themselves in different ways. By extension, $\mathrm{s} / \mathrm{he}$ is also getting them to learn language by exposing them to a variety of ways in which language can be used. The teacher should be the model. The challenge for the teacher then is to be clear in the type of questions asked as well as the commands and the instructions given. The teacher will also find it useful to allow the pupils time to respond and to practise in groups. Such activities provide them with opportunities for classroom talk which is an important component of language teaching and learning. For many pupils, the only time they speak in English is when they are in the classroom and with the teacher. .Such an opportunity should be utilized to the maximum. the basic teaching unit.

Competences To Be Developed $\quad$ Performance Indicators

Ability to:

a) Respond to Yes/No questions correctly. E.g.

- Did you see my book on top of the table?

- Have you finished your work?

- Can I borrow your pen?

- Would you like to go out?

b) Respond to true/false questions e.g.

- Lake Victoria is found in England. (True/False)

- $\quad$ Camels eat meat. (True/False)

- Nairobi is the capital city of Kenya. (True/False)

- Kangaroos are found in Australia. (True/False)

c) Respond to wh- $\boldsymbol{\&}$ how questions in a sentence. These are aimed at getting more than a one-word answer. E.g.

- What is your name?

- Where do you live?

- $\quad$-When is your birthday?

- How do you make a cup of tea?

d) Respond to a series of orders/commands by doing E.g.

- Sit down!

- $\quad$ Close the window.

- $\quad$ Stop making noise!

- Take out your books.

e) Respond to a series of simple instructions $e$.g.

- Write down your name using a blue pen.

- Make a straight line, with girls in front and boys behind.

- $\quad$ Stand back to back with your partner and join your hands above your heads.

f) Respond to a series of requests. E.g.

- Let me use your ruler.

- $\quad$ Please give me a rubber.

- Could you please help me move this table?

- $\quad$ Please pick up the rubbish
The following are ways in which the pupils ability to listen to commands, instructions and requests and respond appropriately can be assessed.

- Ask learners questions that require Yes/No;

True/False answers from a passage or a story the learners have read or heard, or from their environment, experience or background knowledge.

- $\quad$ Ask the wh- \& how questions drawing from the learners' own environment and experiences. Learners should be expected to respond in complete sentences rather than in single words.

- Ask learners to ask you and each other similar but not the same questions, following your examples, and also to provide answers.

- Give the learners a series of commands based on their daily activities or experiences, and ask them to respond in whatever way they want. The learners' responses should be prompt and appropriate. This activity can even be turned into a game where the class is divided into two groups

- $\quad$ and the first to respond is awarded points.

The best team should be rewarded.

- Ask learners to role-play by giving simple instructions. The weaker learners should be given the opportunity and time to give and respond to instructions. Give learners an opportunity to make and respond to various types of requests.

Create a familiar situation where learners act out making and responding to requests. 


Engaging Pupils
This lesson can be very lively and should include activities that the pupils
can do easily.

- Listening to a narrative should be an enjoyable activity in which the pupils are engaged in listening to a narrative then responding by giving appropriate answers to a variety of questions. The narration should not be disrupted by asking questions in between as this breaks the flow of ideas. However, rhetorical questions can be asked to enhance concentration. Language games could also be played, for example, the cat and mouse language game where the cat, after capturing the rat asks it how he wants to be eaten. There should be questions, answers and pleas and lastly instructions from the rat on how to be eaten when the cat becomes adamant and is determined to eat the rat. The rat then commands the rat to do specific actions that would make it easy to be eaten. Other interactive games and activities should help the learners practise asking and responding to questions as well as giving instructions and commands. Simulation and role play are possible techniques of teaching in this lesson.

- Mock interviews and dialogue are other very useful techniques as the pupils can pretend to be anyone that they know e.g. a police officer interviewing a suspect, a doctor interviewing a patient and a head teacher giving his students instructions on how to clean the school compound.

- The teacher could take the pupils outside the classroom and get them to perform a number of drills that require following of commands and instructions. This can even be turned into a competition so that appropriate marks are given to the team that listens keenly and follows instructions appropriately.

- Since commands are usually short and straightforward, it is possible to get even the slower learners to give them by encouraging most of the learners to give at least one command.

- You can also have your learners sing songs that require them to make requests. The teacher should be the model by singing a song first for learners to emulate.

- A variety of pictures could be brought to the classroom and distributed to the learners. Sources of such pictures could be newspaper cuttings, magazines, story books illustrations and real pictures. Learners could then be asked to pose questions to their partners of what they can see in the picture. The partner is expected to respond by giving an answer from the picture.

\section{Enrichment Activities}

After class time, the teacher should engage the learners further by having them do home work by asking them to list down at least five questions, commands, requests and instructions that they hear others give, either at home or in school. Learners could also be asked to make their own sentences using the list they had made. Other activities that learners could do with their peers are:

- Playing language games that they are familiar with.

- Listening to instructions then responding by following them.

- Interacting with audio visual materials like radio or $\mathrm{TV}$

- Drawing pictures following instructions

- Writing dictations or short sentences

- Dramatizing giving and following instructions and simple

- commands

- Using the Physical Education lesson to practise giving and

- Following simple commands and instructions.

- Following instructions from their Science books on how to

- make things or do simple experiments e.g. making a kite,

- identifying types of soil

- Practicing simple miming activities

\section{Resources}

Audio visual materials, charts, a variety of play-things, teacher/ pupil demonstration, other subject text books, dialogue, songs, pictures. 